\title{
The value of eliciting dreams in general psychiatry
}

\author{
Sally Mitchison
}

Dreams have been described as "an endangered species" in general psychiatry nowadays (Holmes, 1991). Liam Hudson (1985) suggests the danger derives from a society which has embraced a naïvely reductionist, oversimplified understanding of neurophysiology. But Hudson also sees a threat to dreams from the increasing variety of visual imagery available for personal creative adaptation through television, computer programs and video recording. Researching this article, I was unable to find a single reference to dreams in the British Journal of Psychiatry over the past 12 years. Theories about dreams are taught to trainee psychiatrists as historical background. In recent years there has been a revival of psychiatric interest in only one kind of dream 'flashbacks' of traumatic experiences as a feature of post-traumatic stress disorder.

The paradox is that psychiatrists remain deeply interested in the quality and quantity of their patients' sleep. Insomnia is frequently the symptom which drives depressed patients to seek help. Persistent insomnia in depressive illness has been identified as a specific risk factor for suicide (Morgan et al, 1998). It has been suggested that sleep disturbance may be the primary experience underlying somatic symptoms of depression (Kirmayer, 1984). A good night's sleep is often what is most craved by our patients. It seems somewhat perverse to enquire about the quantity and duration of sleep but to ignore the subjective experience of sleep as dream time.

Although psychiatrists may have lost interest in dreams, patients have not. Dreams are not infrequently reported in psychiatric interviews, presumably in the hope that the psychiatrist may be able to explain or comment on them. How disappointing if the psychiatrist seems uninterested, particularly if a dream puzzles or disturbs the patient. The message received is that dreams are of no particular interest or relevance.

I suggest that ignoring dreams impoverishes our understanding of our patients. It also closes off areas of personal enquiry and exploration that are potentially fruitful and enabling for patients. The expression of continuing interest in dream life "What do you think about when you are asleep?" can contribute to the patient's recovery of a sense of autonomy and psychological health. 'Reading' dreams - that is to say, encouraging a patient to try to make sense of dreams - is a hermeneutic activity, one concerned with meaning. And meaningless experiences, far from being experienced as unimportant, often generate feelings of hopelessness, despair or even terror. These sorts of feelings call on all our skills as psychiatrists. What is crucial for many patients at risk of being overwhelmed by such feelings is the experience of being understood. If there were no other value to eliciting dreams this would be a sufficient justification. But eliciting dreams can also lead to an appreciation of conflicts and concerns that a patient may not otherwise be able to express. Exploring these sometimes releases an unsuspected capacity for healing and growth.

\section{Classic analytic dream theories}

In the elaboration of his theory of dreams, Freud rejected the notion of pre-cognition. To regard dreams as foretelling future events, as many did a century ago, is to entertain a simplistic view of the future as a predetermined process which can be unfolded

Sally Mitchison undertook a higher training in both psychiatry and analytic psychotherapy. She holds a joint post which allows her to pursue her (waking) dream that analytic thinking might be used to shape and inform psychiatry at a practical, everyday level. Upper Poplars, Cherry Knowle Hospital, Ryhope, Sunderland SR2 ONB. 
and read like a reel of film. He came to regard them instead as compromises between primitive wishes and impulses and the need to repudiate such urges which develops while growing up and which he located in the superego. Freud described a 'latent' content of dreams. He saw this as a response to unresolved daytime experiences from the individual's unconscious mind, which generates libidinal and aggressive wishes. The compromise is that the underlying wish or impulse is allowed fulfilment but in a fashion sufficiently altered and disguised to render the 'manifest' content of the dream sufficiently acceptable for sleep to be preserved. He called this process 'dream work'. The concerns of the unconscious are, he argued, the primary human ones of the body: birth, death, nakedness, parents, children, siblings "and one thing more" - sex (Introductory Lectures in Psychoanalysis, quoted in Bateman \& Holmes, 1995). Although here Freud separated sex from other concerns and mentioned it last, experience led him to emphasise repressed sexual urges to a degree that changed society. As post-Freudians, we now see ourselves as knowing but formerly naïve about our sexuality, especially in infancy. This view is, of course, capable of coexisting with a degree of continuing repression of sexual urges.

Dream work, according to Freud, starts during the waking day but accelerates in sleep. Freud came to see symbolisation as a crucial part of this process. Symbols are personal and include elements from the forgotten past. Bodily symbols are common: a 'box hedge' for pubic hair, a 'scarlet pimpernel' for a nipple. Symbolism may be based on the universal experience of hearing words before knowing how they are spelled: 'Barmouth', 'Maidenhead', 'Hyde Park','hymn' for him, 'sea' for see, and so forth. Ella Sharpe reports a patient who dreamt "Iona Cathedral". Her book on dream analysis (Sharpe, 1937) reflects her background in teaching literature before training as a psychoanalyst. She draws our attention to 'dead' metaphor, especially where it concerns body imagery: a 'striking' thought, a 'seminal' idea. The key idea is that for the unconscious words may acquire a secondary meaning without losing their initial, concrete meaning. In emphasising the personal quality of metaphor in dreams what is meant is not just that symbols are individual but that they refer to the physical person:

\footnotetext{
"there seems to be a general, innate tendency to apprehend all objects that are not ones self by likening them to organs and processes which are ones self" (Rycroft, 1979).
}

Our everyday speech makes frequent references to 'legs', 'head', 'neck','eyes','fingers', and so forth in describing objects and the natural world about us. We speak of 'yawning' chasms, 'howling' winds, of a tale being hard to 'swallow' or of a situation being difficult to 'stomach'.

In addition to symbolisation, Freud argued that dream work involves condensation, a process whereby one word or image contains several meanings when 'unpacked' in dream analysis. He thought that further disguising of the latent content of a dream is accomplished by displacement and reversal: 'top' for bottom, 'you' for me, 'chart' for fart and so forth. His concept of dream work also includes dramatisation or representation, a process whereby words come to be represented visually -a 'yew' (you) tree for example - and secondary elaboration: the undeniable editing and tidying up that we resort to when reporting dreams. Sharpe suggests that all the figures of speech found in poetic diction are used in dream work. Many writers have compared dreams to poetry and have commented on the use of metaphor in both. Not everyone, though, would agree with Freud that the primary function of metaphor in dreams is one of disguise.

Jung rejected Freud's concept of dream work. He saw dreams as expressive and argued that the function of symbols in them was to reveal rather than to disguise. While Freud regarded dreams as protecting sleep, Jung suggested that we dream all the time but, when awake, consciousness supersedes and prevents awareness of dreams. Like Freud, Jung believed that dreams come from the unconscious but he saw them not as expressing forbidden wishes or impulses but as bearing messages to our conscious selves from our own early histories, from our disavowed 'shadow' self and from the collective unconscious in the form of archetypes. Knowledge of these archetypes allows a dream to be read in a cultural and universal context. Dreams contain, in other words, a message from our soul which we should heed. With encouragement and training, this message can be clarified and amplified once the dreamer has awakened. 'Active imagination' and, more recently, 'visualising' extend this process.

\section{Later analytic theories}

Rycroft (1979) is closer to Jung than to Freud in his account of dream analysis and in his view of the function of dreams, although he rejects the concept of the collective unconscious. He believes that dreams can contain straightforward and reasonably accessible messages from one part of the self to another. Dream interpretation, he suggests, is like translating from one language to another. He cites a 
dream described by E. A. Bennet as an example of a message from a disavowed part of the self. Bennet describes how a meticulous banker recurrently dreamt of repelling an intruder from his home. The intruder went from window to window and the banker chased round his house, securing each window in turn. Eventually the intruder gained on the banker and burst in through the front door, at which point the banker awakened. Rycroft suggests that the intruder represents the banker's 'shadow' - all the parts of himself which he has repudiated.

Rycroft objects to Freud's separation of sex from the other fundamental human concerns. He views symbolism in dreams as linking affective experience with bodily experience. Dreams are best understood as a form of "self-communing". They contain messages, he argues, concerning our mortality, our origins - literally and socially - our autonomy and our re-creation of our selves, literally or symbolically. In other words, dreams reflect both our bodily experience and our existential concerns.

A similar view of dreams as existential statements is held by self-psychologists. Bateman \& Holmes (1995) cite Kohut as referring to "self state dreams" and suggest that:

"all the 'characters' in a dream represent parts of the patient's self and... aggression, sexuality, anxiety, persecution, retribution, etc may be split off from the waking self".

This approach to understanding dreams is one that can be experienced as profoundly illuminating by patients recounting dreams in ordinary psychiatric contexts.

\section{The contribution of neurophysiology}

Sleep is essential to human beings and animals, despite the attendant risk of relaxed vigilance. It is not clear exactly why we need to sleep nor what the function is of the different phases of sleep. In 1953 it was discovered that dreams occur in association with rapid eye movement (REM) during paradoxical sleep - so-called because in it the body is relaxed but the brain active. It was initially thought that dreaming occurred only in REM sleep and was the product of random discharges from the brain stem. Crick \& Mitchison (quoted by Hudson, 1985) suggested that dreaming disposed of accumulated images and impressions which the brain needed to discharge in order to preserve more important functions. Dreaming is, in other words, a mental waste disposal system: we dream in order to forget.
Subsequent sleep research has demonstrated that dreaming takes place in slow-wave sleep as well as REM sleep. REM sleep dreams are what we consider 'dream-like' in their bizarre, internally contradictory, frequently impossible nature. But non-REM sleep dreams are described by subjects woken from them as more like daytime thoughts or musings (Hudson, 1985). Hobson's 'activation-synthesis hypothesis' of 1988 (quoted by Bateman \& Holmes, 1995) suggested that dreaming orders and stores information for improved future retrieval, focusing especially on recently activated neuronal pathways ("the day's residue" to use Freud's phrase). (Students' memory of lessons is impaired if they are prevented from dreaming (Burne, 1998).) Initially it was suggested that the narrative aspect of dreams is a result of the brain compulsively trying to construct meaning out of this regular process of recapitulation and organisation. Quite why the brain should do anything so evolutionarily nonsensical as to make sense out of nonsense was not addressed in this hypothesis.

\section{Dreaming and remembering}

Matters become a little clearer if memory is understood as a more complex process than simply one of mental retrieval and filing. Bateman \& Holmes (1995) refer to Solms' work of 1995 which, they argue, leads one to consider the neurological function of dreaming as a complex, representational process. This is, perhaps, linked to the capacity to remember and to forget. Rycroft (1979) draws our attention to the importance of selective forgetting if our minds are to function optimally. Were they cluttered with the everyday detail of each one of our days we would risk overload and breakdown. This is precisely what the Russian neurologist Luria (1975) described in his monograph on a patient with a phenomenal, cinematic memory for detail.

If one function of dreaming is reorganising and selecting experience for future reference, a link can be made with the psychoanalytic view of recurring dreams. Recurring dreams of rushing to catch a train, sitting an examination, travelling towards a city, being threatened by a tidal wave, finding an unknown room in one's house and the like are common experiences. Such dreams, Rycroft (1979) suggests, indicate the existence of an unresolved problem. He sees changes and developments in recurring dreams as indicative of self-development and the emergence of either a solution or a crisis brought on by the problem. Sharpe (1937) suggests that the well-analysed individual experiences no 
repetitive dreams. The psychoanalytic view of recurring dreams as indicative of significant unacknowledged conflict may be influenced by the common experience that such dreams are accompanied by unpleasant feelings, typically fear or anxiety. Little seems to have been written about recurring dreams with agreeable or even ecstatic affect. Sometimes such dreams are simply of a blank or white screen. Lewin (quoted by Rycroft, 1979) suggests that this may symbolise the maternal breast. This might seem fanciful were one not forced to acknowledge the repeated bodily experiences encountered in dreams, both alluded to symbolically and expressed directly. Blissful dreams of pure white light can be construed as fragments of early memory, representations of unconscious desire, or experiences akin to mystical states as described in, for instance, The Tibetan Book of the Dead (EvansWentz, 1927). Peter and Elizabeth Fenwick (1998) describe several transcendent, mystical dreams which show a remarkable similarity to near-death experiences and which leave the dreamer with an enduring sense of inner peace.

\section{Dream recall, play and the capacity for psychological change}

Studies conducted in the sleep laboratory in Edinburgh suggest that although we all dream, convergent thinkers who do best with analytic, logical tasks recall dreams less well than divergent, lateral thinkers who are more at ease with the imaginative and non-rational (Hudson, 1985). The capacity to make creative links to our dreams may be linked to the capacity to play, which can be cultivated or suppressed and which many adults seem gradually to lose. Play contains an inherent metaphor. The recognition of this is what allows us to distinguish playful actions from serious ones. Recognition of metaphor and a degree of conscious appreciation of it, albeit perhaps intuitive rather than academic, is an important component of psychological-mindedness (Coltart, 1988). This capacity facilitates psychological change and growth. It is not a quality that a person either has or does not have-more a talent that seems to abound naturally in some but that can be encouraged in others. One particularly rewarding experience in general psychiatry is observing the gradual emergence of psychological-mindedness as patients with neurotic disorders progress in their understanding of and capacity to cope with their symptoms.
One important task faced by many patients with such disorders is to come to feel in charge of themselves and their symptoms, actions and destinies. Often, psychiatric symptoms are experienced as frightening phenomena that take over without warning, explanation or precedent. The sense of helplessness that this engenders, often in individuals who have previously not felt particularly in charge of themselves, is an obstacle that has to be overcome before a sense of well-being is restored. Medication often plays an important part in recovery but unless the patient comes to feel in control, medication alone may well not suffice to ensure recovery. All too often patients relapse when medication ceases.

An important and, in my view, underrated skill in general psychiatry is to be able to encourage psychological thinking and enquiry and to encourage patients to develop psychological explanations for distressing symptoms, experiences or behaviour. Most of us are drawn into psychiatry by curiosity about what makes people 'tick'. This interest forms the core of psychological-mindedness. The capacity to think psychologically is best viewed as complementing, rather than being replaced by, scientific understanding.

Although interviews in general psychiatry often have to exclude the presence of psychosis or dementia, the 'bread and butter' work of the profession is with patients who suffer from neither of these. It is appropriate that psychiatric trainees are taught to conduct mental state examinations; but it is a pity that in the process of understanding the patient, the importance of the patient coming to feel understood is frequently overlooked. A worryingly small proportion of patients report feeling helped by their psychiatrist (Rogers et al (1993) quoted by Thomas et al, 1996).

Empathy alone is not sufficient, although without it the enterprise is likely to fail. Nor is it adequate to establish what degree of insight the patient has into his or her disorder. One can know there is something wrong without having a clue as to why. The nature of patients' understanding of their symptoms has to be elicited and then, as we know all too well, often has to be gently coaxed and encouraged until a psychological dimension emerges. Psychiatric disorders do not simply overtake a patient; they develop out of an interaction between character, psyche and circumstance. "Why now?" is one question that can open the door of selfunderstanding. There is, of course, no single answer to this question. Reflection on it promotes an unfolding understanding which, over time, will prompt different answers. These are best seen as additional rather than alternative explanations. Some one may become depressed because he or she 
has lost a partner and because in so doing he or she lost the hope of being understood and appreciated that was embodied in the relationship; and because he or she became more vulnerable to such a loss of hope after the early loss of a parent; and because other opportunities for the expression of creative or reparative impulses were reduced by unemployment, ill health, children leaving home or other experiences of adult life. (Someone may also carry a familial vulnerability to depression, but focusing on this tends not to be encouraging or enabling for the patient.) What is important is that the psychiatrist does not labour to establish a single or even a precipitating experience that will explain the presence of a disorder, but that he or she is instead prepared to embark on a journey of discovery with the patient. This depends in part on a willingness to do so based on an appreciation of the importance to the patient of such an enabling relationship. But we also need lines of enquiry and topics of discussion that allow our patients, often reluctant travellers, to find the journey important and worthwhile.

Eliciting dreams is a fruitful way to start. It is not necessary to have a teleological view of dreams, seeing them as occurring for any particular intrapsychic purpose. The origin of dreams may be random, but interesting stories form revealing important personal themes and preoccupations. The story may emerge through an expression of the patient's unconscious mind, in the editing and tidying up process that accompanies all accounts of dreams, in the intersubjective space in which a particular dream is selected and described to a psychiatrist, or in subsequent reflection. What is important is that the story emerges and that its bearing on the patient's difficulties comes to be appreciated by the patient.

\section{Dream analysis as a creative activity}

Most ordinary people experience dreams as events. Where the psychiatrist can help is by approaching them more as creations:

"Dreams are best understood...if one forgets all theories about them and ceases to think of them as discrete phenomena or items of experience but instead responds to them as glimpses of the dreamer's total imaginative fabric" (Rycroft, 1979).

Dream interpretation is probably best approached as a form of creative reflection between the psychiatrist and the patient (O'Neill, 1990). In this respect it helps to attend to the context in which a dream is narrated: what preceded it? Why now? It is not just the content but also the manner of narration that is important. Commonly, patients offer additional material in discussion after relating the main dream: an overlooked part of the dream, a detail which now feels significant, a clarification. These additions form part of the patient's associations and are an important part of the creative activity. They are more likely to occur if the psychiatrist refrains from leaping into interpretive feedback. The 'meaning' of a dream may seem blindingly obvious but what matters above all is the meaning that the patient comes to attribute to it - which is not infrequently a surprise - and the process by which this meaning is arrived at.

I find it helpful to write down patients' dreams at the time they are reported. This signals that I consider them significant and might wish to return to them in future. The process of transcription allows for clarification and the recall of additional details. Often associations to the dream are offered spontaneously at this point. It is best not to interrupt the flow but to pause before making any comment to allow time for ideas to be collected and put into words by the patient. But early on in the discussion, it is necessary to establish what the affect of the dream was. It cannot be assumed, for instance, that dreams of falling are terrifying; the experience for the dreamer may have been closer to taking flight into the air or retreating from a daunting task and finding a soft landing. Once the 'feeling tone' of the dream has been established the process of association to the dream can be prompted by asking "What do you make of it?" Alternatively, one might choose to focus on some feature of the dream and enquire about or simply draw attention to it. Exploration of the dream need not take place immediately. It is often helpful to return to a dream at other points later on in the interview or subsequently. If the psychiatrist can allow such a weaving back and forth in the conversation, it is surprising how often new meaning emerges. Links can be made between a theme in the dream, such as having to do things on one's own or missing an opportunity, and the patient's current preoccupations and life experience. This encourages introspection, an important step in the process of coming to understanding oneself.

Although some preoccupations and concerns are individual, many relate to common existential worries and fears. Adult life exposes us all to cumulative experiences of loss, ageing, sickness, death, deceit and disappointment. These experiences prompt thoughts about transience, mortality, the imperfectibility of human nature and the sadness of things generally. Some cultures encourage more discussion of such matters than others. An overemphasis on material prosperity and technology may reduce the opportunities for people to think 
and talk about these important matters. Experiences then risk being construed as uniquely personal with attendant shame and fear of madness. An important step in coming to understand the universality of many experiences and to accept them as normal is to talk to someone else about them and have them understood. One of a psychiatrist's functions is to be that initial someone else. It follows that often the psychiatrist does not need to arrive at an interpretation of all or part of a dream for discussion of issues related to it to be fruitful.

Interpretations can, however, allow a patient to reflect on some matter previously overlooked or even disavowed. As has already been suggested, it is possible to construe different characters in a dream as standing for different aspects of the dreamer. Dreams about one's own house may represent one's body, one's self, or our original 'house' - our mother's body.

A young woman, in the process of a painful separation from her partner dreamt repeatedly that she returned home to find their house on fire. In the dream she felt distressed by this but curiously resigned to it as well.

When she recounted this dream her initial thought was that it represented symbolically how 'gutted' she felt by the parting. Later she was more aware that it was their rather than her house that was on fire. She came to see the fire as standing for split-off feelings of aggression with which she was not in touch at the time. Her feelings of resignation, she decided, suggested that her anger had kindled the flames.

Symbols, it must be remembered, are both personal and shared. A snake, for instance, may stand for some repulsive, sinister or semi-hidden aspect of the self. Our Christian antecedents might suggest that a snake represents sex or the penis. Hudson (1985) contrasts Ruskin's terrifying dreams of "loathsome snakes", in which he seemed to be grappling with his increasingly problematic adult sexuality, with Kekule's reported dream of guessing the ring structure of benzene after an inspiring dream of a snake coiling its tail into its mouth. What matters is what the patient makes of his or her dreams rather than the psychiatrist's interpretation, however neat or clever.

Where the psychiatrist can work creatively with patients on dreams is in opening up possible layers of meaning that are new to the patient. For instance, devout dreamers may worry that God seems absent from their dreams. God may appear in an altered form - "In my father's house are many mansions". The important question, though, is what does $\mathrm{He}$ say? Dreams in which the dreamer is terror-struck are common. It may help to accept the occurrence of such dreams to understand the normal cataleptic experience of REM sleep in which muscles can be so deeply relaxed that it is truly impossible to move or scream. Dreaming of finding a previously undiscovered room or wing of a familiar house might prompt enquiries such as "What do you think you're going to furnish it with?" or "What do you think you'll find in your new development?" Neville Symington (1986) calls such dreams 'structural' and says that, in analysis, they can be construed as representing growth in self-understanding.

\section{Conclusion}

I have briefly summarised some analytic and neurophysiological theories. It is suggested that dreams should neither be reified nor ignored, but instead approached enthusiastically as a bridge offered into the patient's inner world. Dreams offer the psychiatrist an opportunity to work creatively with patients, eliciting their current fears and preoccupations and allowing a reflective space in which these can be further elaborated. This process promotes psychological thinking and self-understanding, important components of psychiatric recovery.

\section{References}

Bateman, A. \& Holmes, J. (1995) Introduction to Psychoanalysis. Contemporary Theory and Practice. London: Routledge. Burne, J. (1998) Dream a little dream. Guardian, 18 Septeber.

Coltart, N. E. C. (1988) The assessment of psychologicalmindedness in the diagnostic interview. British Journal of Psychiatry, 153, 819-820

Evans-Wentz, W. Y. (1927) The Tibetan Book of the Dead. London: Oxford University Press.

Fenwick, P. \& Fenwick, E. (1998) The Hidden Door: Understanding and Controlling Dreams. Headline.

Holmes, J. (1991) The democracy of the dream. British Journal of Psychiatry Review of Books, No. 2, 20-23.

Hudson, L. (1985) Night Life. London: Weidenfeld \& Nicholson

Kirmayer, L. J. (1984) Culture, affect and somatization, Part II. Transcultural Review, 21, 237-262

Luria, A. R. (1975) Mind of a Mnemonist: A Little Book about a Vast Memory. Harmondsworth: Penguin.

Morgan, G., Buckley, C. \& Nowers, M. (1998) Face to face with the suicidal. Advances in Psychiatric Treatment, 4, 188196.

O'Neill, K. (1990) Royal road to the unconscious. Psychiatric Bulletin, 14, 37-38.

Rogers, A., Pilgrim, D. \& Lacey, R. (1993) Experiencing Psychiatry: Users' Views of Services. London: Macmillan.

Rycroft, C. (1979) The Innocence of Dreams. London: Hogarth Press.

Sharpe, E. F. (1937 reprinted 1978) Dream Analysis. London: Maresfield.

Symington, N. (1986) The Analytic Experience. London: Free Association Books.

Thomas, P., Romme, M. \& Hamelijnck, J. (1996) Psychiatry and the politics of the underclass. British Journal of Psychiatry, 169, 401-404 


\section{Multiple choice questions}

1. Analytic thinkers have considered dreams as:

a employing the same figures of speech as poetry

b reflecting the 'collective unconscious'

c portents

d containing messages from the hidden side of the personality

e reflecting the dreamer's existential condition.

2. 'Dream work':

a occurs when awake as well as during sleep

b includes condensation

c can involve punning

d reveals the latent content of the dream

$\mathrm{e}$ is a form of projection.

3. Regarding dreaming and sleep phase:

a dreaming occurs both in REM and nonREM sleep

b individuals deprived of REM sleep become somnambulistic

c dreaming is thought to form part of the encoding process of memory

d dreaming is thought to allow us to 'forget' daytime experience

e different types of dreams occur in different phases of sleep.
4. Psychological mindedness:
a has recently been discovered
b depends on intuitive understanding of figures of speech
c in a psychiatrist is an indication for psychotherapy training
$d$ includes enquiries about the timing of symptoms
e is genetically pre-determined.

5. Regarding symbols in dreams:
a dreaming of a house often symbolises the self
b dreams of stealing or theft warn of burglary
c dreams of snakes indicate a fear of seduction
d political symbols, e.g. the hammer and sickle, are similar to those that occur in dreams
e symbols in dreams are highly personal.

\section{Commentary}

\section{Arthur Crisp}

\begin{abstract}
"Sleep that knits up the ravell'd sleeve of care, The death of each day's life, sore labour's bath, Balm of hurt minds, great nature's second course, Chief nourisher in life's feast" (Shakespeare: Macbeth, Act II, Scene 2).
\end{abstract}

Dreams are not so much a modern preoccupation but, throughout recorded human history, importance has been attached to them as being self-revealing and as vehicles for messages and portents. Recognition that we daydream is also time-honoured.

As Mitchison points out, psychiatrists today take a serious interest in aspects of their patients' sleep whether or not there is a complaint concerning it, but this rarely extends to an interest in a patient's dreams except when nightmares are to the fore. More often, in the clinic, sleep is presented as a soughtafter refuge from wakefulness and little thought is 